\title{
Pseudo-capsule "coffin effect": How to prevent penile retraction after implant of three-piece inflatable prosthesis
}

\author{
Enrico Caraceni ${ }^{1}$, Lilia Utizi ${ }^{2}$, Giovanni Angelozzi ${ }^{3}$ \\ Department of Urology, Civitanova Marche Hospital, Italy.
}

\begin{abstract}
Summary Objective: Following three-component implantation of a penile prosthesis, some patients are dissatisfied with their penile length. This may be due to the procedure by itself or pre-existing risk factors or psychological reasons. We supposed that formation of a restricted pseudo-capsule due to a late prosthesis activation can inhibit later system expansion. We aimed to identify the presence or absence of penile retraction after implant and to prevent it by immediate prosthesis activation after implantation.

Material and methods. Forty-six patients operated with three-piece inflatable penile prosthesis (AMS $700 \mathrm{CX}$ o $L G X)$ were enrolled. In 27 patients prosthesis was first activated four weeks after surgery (NEA group) and in 19 patients prosthesis was activated immediately after surgery (DEA group). Length and girth of the penis was evaluated before (in DEA group) and after the surgical procedure. Results. The average post implant dorsal length of the erect penis in group NEA was found $3.28 \mathrm{~cm}$ shorter than in group with early activation (DEA). In DEA group there was no lenght difference between pre-operative stretching $(14.57 \mathrm{~cm})$ and post operative erection $(14.98 \mathrm{~cm})$. When early activation was not performed, the clinical result was a smaller penis in erect phase.

Conclusion. Reduced lenght of the penis after implantation can be caused by the presence of a pseudo-capsule that limits the elongation of the prosthesis and of the penis ("coffin effect"). Timing of first activation seems to be the key in order to prevent the risk of penile retraction after implantation. Early activation is identified as the best measure to maintain the length of the pre implant erect penis after the prosthetic hydraulic implant.
\end{abstract}

KEY WORDS: Penile prosthesis length; Penile retraction; Early activation; LGX penile prosthesis; AMS 700 CX penile prosthesis; Coffin effect, Three piece penile prosthesis; Size of the penis; Shortening of the penis.

Submitted 23 December 2013; Accepted 29 March 2014

\section{INTRODUCTION}

Following implants of a penile prosthesis some couples are dissatisfied with penile length and girth (1-3). This may be one reason for implant dissatisfaction: disap- pointment can be severe and in some cases can lead to loss of use of the prosthesis even when it is working well. First Montorsi et al. in 2000 (4) reported that about 30\% of patients complained a decrease in penile size after three-piece prosthesis implantation.

The authors explained the finding as follows: this dissatisfaction is linked with the loss of engorgement of the glans or to the recall of the natural preexisting erection, or to the pre-operatory penis size loss.

Deveci et al. in 2007 (5) wrote there were no statistically significant differences in penile length after the surgery compared to preoperative measurements in a group of 56 patients affected of erectyle dysfunction (ED) of various nature, excluding Peyronie's disease. Patients had the penile length measured at the beginning of the operation prior to device implantation (stretched flaccid length), and at 1 and 6 months postoperatively (dorsal length with activated prosthesis). Length was measured from the pubic bone to meatus along the dorsum of the shaft. They did not find significative difference in preoperative stretched penis and postoperative penile length with the activated device. In their experience about two of three patients (72\%) surprisingly complained decreased in penile length. They explained that this feeling might be related to a comparison with their penile length before the onset of ED, or to pre-implant penile length reduction related to radical prostatectomy or other penile fibrotics changes. They concluded that patient and partner education from the beginning may limit unrealistic expectations after implantation. Patient should be advised that penile implants may not restore the full length once achieved by natural erections. Treatment satisfaction appears not to be fully dependent on subjective penile length and then the failure in sizing (told by $72 \%$ of their patients) is not real but subjective.

Montague (6) in 2007 published a review of literature on the penis size matter after penile implants. He recognized that it is likely that inflatable penile prosthesis implantation does not provide a prosthetic erection quite as long as a natural erection. He believed that the loss of penile sizing could be attributed to the fact that prosthetic erection does not include glans tumescence or to penile retraction due to preoperatory factors, like radical prostatectomy. However, he concluded it is necessary to speak to the patient telling him: "your preoperative

No conflict of interest declared 
stretched penile length will approximately be like your erect length after prosthetic surgery".

Shaeer et al. (7) in a recent paper published in Sexual Medicine in 2010 about his surgical technique to improve penile size after inflatable prosthesis implantation, classified the possible causes of the loss of penis size after implantation. They wrote "decrease in size may sometimes be a mental impression due to unrealistic expectations, poor counseling, or dysmorphophobia".

Alternatively, diminished phallic size may be real and due to the inherent nature of the procedure or to a preexisting pathology. The latter includes cases of fibrosis following radiotherapy, neglected priapism, and Peyronie's disease, all of which exhibit shortening and/or narrowing, or cases with overhanging suprapubic fat leading to concealment. In such cases, diminished size is not a result of the procedure itself, but rather due to an ignored preexisting complaint of undersized phallus, shadowed by erectile dysfunction (ED), a complaint that the physician failed to recognize and address. On the other hand, actual diminution in size may be iatrogenic, caused by the procedure itself. Shaeer and al recognized that there is a real loss of penis size after implantation techniques and proposes expansion to correct the defect and improve patient and partner's satisfaction. However, he lacked the demonstration of his statements about the real loss in size after installation. His work is only about the surgical technique to supersize the penis following penile prosthesis implantation.

Levine and Rybak in 2011 (8) concluded that there is not recognised reliable technique to gain length once the device is placed and proposed the use of external traction therapy prior to inflatable penile prosthesis placement to solve the problem. Moskovic (9) obtained the same results in a case treated using the same method of Levine. Finally, other authors proposed preoperatory Vacuum Device treatment $(10,11)$. We believe the loss of length and girth of the penis after prosthetic hydraulic implant is a multi-factorial phenomenon: preexisting factors like obesity, penile fibrosis (post priapism or post induratio penis plastica), pelvic surgery (radical prostatectomy, cystectomy or abdominal amputation of the rectus) can reduce "per se" penile size $(12,13)$, but in addition to these factors pseudo-capsule formation could play an important role in reducing the penis after implant.

In fact in case of late activation of the prosthetic device a

Table.

Penile elasticity ( $\Delta$ and $\Delta 1)$.

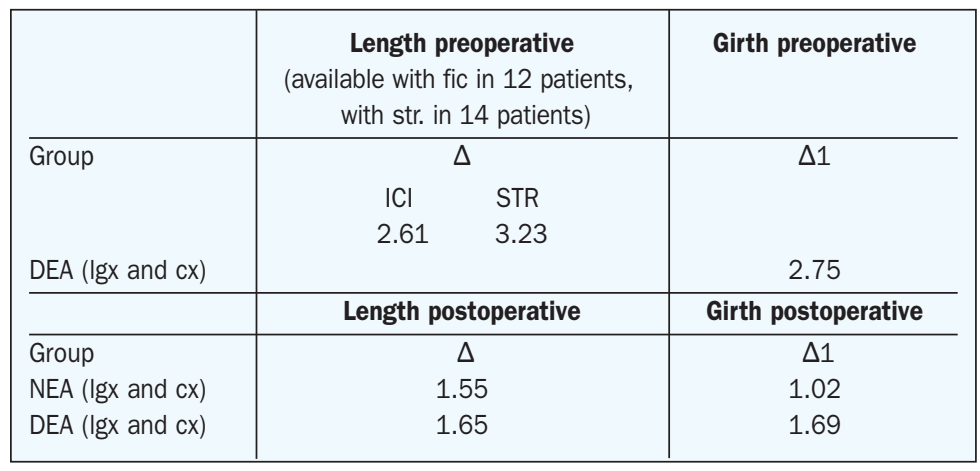

pseudo-capsule can form around the deactivated empty implant that is smaller in size with respect to the fully activated implant. When the prosthesis is activated after three or four weeks, as recommended by the manufacturers $(14,15)$, it cannot expand further due to the resistance of pseudo-capsule, which is so far fully formed. In other words the pseudo-capsule prevents the full prosthesis expansion, thus determining a reduction of the true size of the penis working like an inextensible wall. We have called this phenomenon "coffin effect" of pseudo capsule. The "coffin effect" should be added to other predisposing factors of penile size reduction and it is always present. If the prosthesis is not left inflated immediately after the surgery and for subsequent two or three weeks the result will be a smaller penis with similar dimensions to the non activated prosthesis.

Aim of this study was to identify the presence or absence of penile retraction after implant with three-component prosthesis and to evaluate the possibility to prevent it by immediate activation of the prosthesis after the surgical procedure without use of other device or other surgical strategies before or after the operation (16-19).

\section{Conclusions}

According to our observations we confirmed the occurrence of a "true" penile shortening after prosthetic implant ( $11.70 \mathrm{~cm}$ in the NEA group).

This can be caused by the formation of a pseudo capsule, that develops around the non activated implant that acts as a "wall" that subsequently prevents the prostesis expansion and the potential elongation of the penis after implantation. The pseudo capsule limits the dimension of the penis and the prosthesis can only move like a "sliding door" inside it forward during activation and backward when it is deactivated. The result is a larger penis in flaccid state but smaller in erect phase expecially when early activation was not performed. The implant can work like an expander, if well used, but the size of the penis is limited by the pseudocapsule. This "coffin effect" explains the retraction and the lower elasticity of the penis that can occur after implantation as a consequence of the formation of the pseudo capsule. The decreased elastic capacity of the penis after penile prosthesis implantation involves a lower difference between penile length in flaccid and erect state and larger length and girth of the flaccid penis.

This is confirmed by the observation that early activation as an effective measure to prevent penile shortening after implantation. LGX implant can improve the length (15.35 in DEA group versus 11.90 in NEA group) and girth (12.43 in DEA group versus 11.90 in NEA group) of the penis only if early activated. In conclusions early activation is a measure to prevent the loss of length of the erect penis after implantation.

\footnotetext{
Materials and Methods, Results, Tables and Discussion are fully described in Supplementary materials posted on www.aiua.it
} 


\section{References}

1. Candela JV, Hellstrom WJ. Three-piece inflatable penile prosthesis implantation: a comparison of the penoscrotal and infrapubic surgical approaches. J La State Med Soc. 1996; 148:296-301.

2. Bernal RM, Henry GD. Contemporary patient satisfaction rates for three-piece inflatable penile prostheses. Adv Urol. 2012; 2012:707321.

3. Trost LW, Baum N, Hellstrom WJ. Managing the difficult penile prosthesis patient. J Sex Med. 2013; 10:893-906.

4. Montorsi F, Rigatti P, Carmignani G, et al. AMS Three-piece inflatable implants for erectile Dysfunction: a long-term multi-institutional study in 200 consecutive patients. Eur Urol. 2000; 37:50-55.

5. Deveci S, Martin D, Parker M, Mulhall JP. Penile length alterations following penile prosthesis surgery. Eur Urol. 2007; 51:1128.

6. Montague DK. Penile Prosthesis Implantation: Size Matters. Europ Urol. 2007; 51:887-888.

7. Shaeer O. Supersizing the Penis Following Penile Prosthesis Implantation. J Sex Med. 2010; 7:2608-16.

8. Levine LA, Rybak J. Traction therapy for men with shortened penis prior to penile prosthesis implantation: a pilot study. J Sex Med. 2011; 2112-7.

9. Moskovic DJ, Pastuszak AW, Lipshultz L, Khera M. Revision of penile prosthesis surgery after use of the penile traction therapy to increase erect penile length: case report and review of the literature. J Sex Med. 2011; 8:607-11.

10. Raheem AA, Garaffa G, Raheem TA, et al. The role of vacuum pump therapy to mechanically straighten the penis in Peyronie's disease. BJU Int. 2010; 106:1178-80.

11. Soderdahl DW, Petroski RA, Mode D, et al. The use of an external vacuum device to augment a penile prosthesis. Tech Urol. 1997; 3:100-2.

12. Montague DK, Angermeier KW. Increasing size with penile implants. Curr Urol Rep. 2008; 9:483-486.

13. Sansalone S, Garaffa G, Djinovic R, et al. Simultaneous total corporal reconstruction and implantation of a penile prosthesis in patients with erectile dysfunction and severe fibrosis of the corpora cavernosa. J Sex Med. 2012; 9:1937-44.

14. American Medical System (Ams). Available at the website: http://www.americanmedicalsystems.com

15. Henry GD, Brinkman MJ, Mead SF, et al. A survey of patient with inflatable penile prostheses: assessment of timing and frequency of intercourse and analysis of implant durability. J Sex Med. 2012; 9:1715-21.

16. Borges F, Hakim L, Kline C. Surgical technique to maintain penile length after insertion of an infatable penile prosthesis via infrapubic approach. J Sex Med. 2006; 3:550-3.

17. Henry G, Houghton L, Culkin D, et al. Comparison of a new length measurement technique for inflatable penile prosthesis implantation to standard techniques: outcomes and patient satisfaction. J Sex Med. 2011; 8:2640-6.

18. Hakky TS, Suber J, Henry G, et al. Penile enhancement procedures with simultaneous penile prosthesis placement. Adv Urol. 20123; 314-612.

19. Rolle L, Ceruti C, Timpano M, et al. A new, innovative, lengthening surgical procedure for Peyronie's disease by penile prosthesis implantation with double dorsal-ventral patch graft: the "sliding technique". J Sex Med. 2012;9:2389-95.

\footnotetext{
Correspondence

Enrico Caraceni, MD

Director of Department of Urology - Civitanova Marche Hospital

Civitanova Marche, Italy

ecarace@libero.it

Lilia Utizi, Clinical Psychologist (Corresponding Author)

Sexual Behavior Consultant - Department of Urology - Civitanova

Marche Hospital

Civitanova Marche, Italy

1.utizi@libero.it.

Giovanni Angelozzi, MD

Department of Urology - Civitanova Marche Hospital

Civitanova Marche, Italy

giovauro@yahoo.it
} 